\title{
Beta diversity and latitude in North American mammals: testing the hypothesis of covariation
}

\author{
Pilar Rodríguez and Héctor T. Arita
} Rodríguez, P. and Arita, H. T. 2004. Beta diversity and latitude in North American
mammals: testing the hypothesis of covariation. - Ecography 27: 547-556.

\begin{abstract}
Several hypotheses attempt to explain the latitudinal gradient of species diversity, but some basic aspects of the pattern remain insufficiently explored, including the effect of scales and the role of beta diversity. To explore such components of the latitudinal gradient, we tested the hypothesis of covariation, which states that the gradient of species diversity should show the same pattern regardless of the scale of analysis. The hypothesis implies that there should be no gradients of beta diversity, of regional range size within regions, and of the slope of the species-area curve. For the fauna of North American mammals, we found contrasting results for bats and non-volant species. We could reject the hypothesis of covariation for non-volant mammals, for which the number of species increases towards lower latitudes, but at different rates depending on the scale. Also, for this group, beta diversity is higher at lower latitudes, the regional range size within regions is smaller at lower latitudes, and $\mathrm{z}$, the slope of the speciesarea relationship is higher at lower latitudes. Contrarily bats did not show significant deviations from the predictions of the hypothesis of covariation: at two different scales, species richness shows similar trends of increase at lower latitudes, and no gradient can be demonstrated for beta diversity, for regional range size, or for the slopes of the species-area curve. Our results show that the higher diversity of non-volant mammals in tropical areas of North America is a consequence of the increase in beta diversity and not of higher diversity at smaller scales. In contrast, the diversity of bats at both scales is higher at lower latitudes. These contrasting patterns suggest different causes for the latitudinal gradient of species diversity in the two groups that are ultimately determined by differences in the patterns of geographic distribution of the species.
\end{abstract}

P. Rodríguez and H. T. Arita (arita@ecologia.unam.mx), Inst. de Ecologia, Univ. Nacional Autónoma de México, Apartado postal 70-275, C. P. 04510 México, D. F.

One of the best established biogeographic patterns on Earth is the increase in the number of terrestrial species from high to low latitudes, particularly in the northern hemisphere (Rohde 1999). Several ecological and evolutionary hypotheses have been proposed to explain the pattern, including responses of species diversity to gradients in the intensity of ecological interactions, spatial patchiness, environmental stability and predictability, productivity and energy, available area for colonization, among others (Rohde 1999, Kaspari et al. 2003). In contrast, other studies have shown that computer models in which the ranges of species are randomly arrayed, constrained only by the size and shape of continents, can reproduce some traits of latitudinal gradients in species diversity due to the socalled mid-domain effect (Colwell and Lees 2000, Jetz and Rahbek 2001). However, current models cannot explain satisfactorily the observed spatial patterns for some continents (Bokma et al. 2001, Hawkins and Diniz-Filho 2002) and some of the more basic features of those patterns are still insufficiently explored (Zapata et al. 2003). The effect of scale and the role of beta diversity on the latitudinal gradient of species diversity are only two of such aspects.

Accepted 8 March 2004

Copyright (C) ECOGRAPHY 2004

ISSN 0906-7590 
Beta diversity has been defined in several ways, but in its original and broad sense it refers to the "extent of species replacement or biotic change along environmental gradients" (Whittaker 1972). Following this definition, and considering that beta diversity is an element at least as important as local diversity in determining the diversity patterns at regional scales (Cornell and Lawton 1992), it is surprising that there are no empirical or theoretical rules regarding the relationship between latitude and beta diversity that can compare to those of the latitudinal gradient of species diversity (Gaston and Blackburn 2000). A possible explanation for the lack of generalizations is that different studies have evaluated different aspects of beta diversity (Koleff et al. 2003). While some studies have focused on the differences in species composition between sites, others have attempted to detect zones of habitat or biogeographic transition (Williams et al. 1999), and still others have quantified the relative change in species composition along spatial or environmental gradients (Condit et al. 2002).

A promising approach to the incorporation of the beta component in the study of large-scale patterns is to visualize beta diversity as a scaling factor of species diversity. In a pioneering work, Shmida and Wilson (1985) postulated beta diversity as a factor accounting for the spatial distribution of species as one moves from local to larger scales. More recently, a similar idea has been posed in large-scale studies to analyse the relationship between regional and local diversity (Cornell and Lawton 1992, Srivastava 1999), to interpret the parameters of the species-area relationship (Rosenzweig 1995), and to explore patterns in the scaling of species diversity (Crawley and Harral 2001, Arita and Rodríguez 2002).

If beta diversity is defined as a ratio between the species diversity of a region and the average diversity of localities within that region (Whittaker 1972), it can be shown that beta is mathematically equivalent to the inverse of the average range size of the species occurring in the region, range being measured as the number of localities in which a given species is present (Routledge 1977, Ricklefs and Schluter 1993, Arita and Rodríguez 2002). This relationship can be applied to a broader range of scales including those which are not strictly local (Arita and Rodríguez 2002, 2004). Indeed, the traditional perception of the local scale as a purely ecological level is changing to a perspective of conceiving local assemblages as a set of species whose geographic distribution overlap a particular geographic point, thus determining the "regional point diversity" (RPD) of a site (Arita and Rodríguez 2004, see Ricklefs 2004).

Because of the relationship between beta diversity and the average range size, and because in some taxa the range of species tends to be smaller at lower latitudes, in what has been called Rapoport's rule (Stevens 1989), it would be reasonable to predict a latitudinal gradient of beta diversity paralleling that of species richness and being inverse to that of average range size. However, a distinction should be made between the continental range size (the whole distribution area of a species), and the regional range size (the area covered by a species within a defined region). The regional range is what is correlated with beta diversity. Here we explore the relationships between latitude, regional range size and beta diversity for the fauna of North American mammals.

North American mammals constitute the most thoroughly studied group regarding patterns of species diversity at the continental scale. The negative relationship between species richness and latitude has been reported for all mammals (Simpson 1964, Wilson 1974, Pagel et al. 1991), for non-volant species (Pagel et al. 1991, Kaufman 1995, Shepherd 1998, Kaufman and Willig 1998 but see McCoy and Connor 1980) and for bats (Wilson 1974, McCoy and Connor 1980, Lyons and Willig 1999, 2002, Stevens and Willig 2002), regardless of scale or sampling method. The Rapoport rule holds for all mammals (Rapoport 1975, Stevens 1989, Pagel et al. 1991), the non-volant component of the fauna (Pagel et al. 1991), and for bats (Willig et al. 2003). Analysis of beta diversity of North American mammals has focused on species turnover along bands (Willig and Sandlin 1991, Willig and Gannon 1997), and on the latitudinal trend in beta diversity (Kaufman 1998, Stevens and Willig 2002).

Brown and Lomolino (1998) speculated that if Rapoport's rule holds, as it is the case with North American mammals, both regional species richness and beta diversity should be higher at lower latitudes. However, as the latitudinal trend in species diversity seems to be the same regardless of the scale of analysis (Lyons and Willig 1999, but see Lyons and Willig 2002), one should expect beta diversity not to vary along a latitudinal gradient (see rationale below). In this paper, we show that this apparent contradiction can be solved through the analysis of the covariation in the value of species diversity at different scales, and through the exploration of the pattern of variation of beta diversity along a latitudinal gradient.

\section{The hypothesis of covariation}

We have called the hypothesis of covariation the idea that variation in species diversity along latitudinal gradients is the same regardless of the scale of analysis. Because of the relationship between species diversity at different scales and beta diversity, the hypothesis of covariation provides explicit predictions that can generate testable statistical hypotheses. The components and predictions of the hypothesis are as follows: 
First component: the hypothesis is based on the existence of a latitudinal gradient of species diversity at a given large scale of analysis. At this scale, several regions are defined and the number of species occurring there (which we will call regional diversity, $S_{R}$ ) should follow a latitudinal trend, which can be shown in a log $\mathrm{S}_{\mathrm{R}}$ vs latitude plot (Fig. 1a).

Second component: the hypothesis requires, by definition, gradients of species diversity at different smaller scales that should follow the same trend as the regional pattern. To provide easily testable hypotheses, here we concentrate on a single scale that is smaller than the regional one that consist on sampling points within the regions. This second component can be tested by comparing the slopes of the regression lines of species diversity at the regional scale $\left(\mathrm{S}_{\mathrm{R}}\right)$ and species diversity at
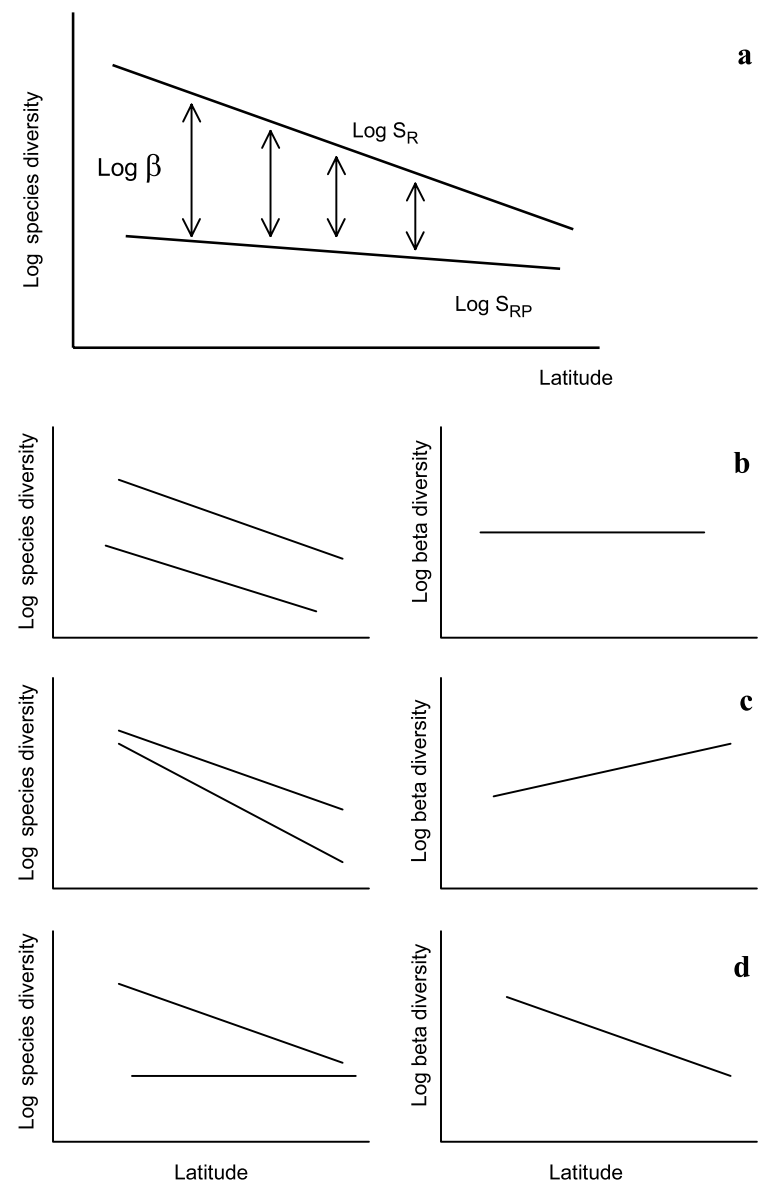

Fig. 1. The hypothesis of covariation states that variation in species diversity with latitude follows similar trends regardless of scale. In a log diversity-latitude plot, the distance between the line corresponding to a regional scale and the line for a smaller scale is equal to the log value of Whittaker's beta diversity (a). The hypothesis of covariation is fulfilled if the two diversity lines are parallel, implying that beta diversity is invariant with latitude (b). If the slopes of the two diversity lines are different, the hypothesis of covariation is rejected, and there is a latitudinal gradient in beta diversity (c and d). the smaller scale of analysis (which we will call regional point diversity RPD; Arita and Rodríguez 2004) ( $\left.\overline{\mathrm{S}}_{\mathrm{RP}}\right)$, both in a log scale, on latitude (Fig. 1a). If the hypothesis of covariation holds, then both lines should be parallel, their slopes being equal (Fig. 1b, left). We compared the slope of the regression line of species diversity using linear statistical model.

Third component: beta diversity should not vary with latitude. Whittaker's (1960) formulation of beta diversity is $\beta=\mathrm{S}_{\mathrm{R}} / \overline{\mathrm{S}}_{\mathrm{RP}}$. Equivalently, $\log \beta=\log \mathrm{S}_{\mathrm{R}}-\log \overline{\mathrm{S}}_{\mathrm{RP}}$, so, in a $\log$ scale, beta diversity at a given latitude can be visualized simply as the distance between the regression lines of regional and regional point diversity by RPD. Assuming that the regression line for the regional diversity has a negative slope, as consistent with available empirical evidence (Kaufman and Willig 1998, Lyons and Willig 1999, 2002), three possible results can be obtained when comparing the slopes of the regression lines for regional and RPD. If the two lines are parallel, implying a latitudinal gradient of RPD similar to that of regional diversity, then the distance between them is constant regardless of latitude, and there is no latitudinal gradient in beta diversity (Fig. 1b). The covariation hypothesis could not be rejected. If the slope of the RPD line is smaller (more negative) than that of regional diversity, then beta diversity would be higher at higher latitudes, rejecting the covariance hypothesis (Fig. 1c). Finally, if the slope of the RPD line is higher (less negative, null, or positive) than that of regional diversity, then beta diversity would be higher at lower latitudes, also rejecting the covariation hypothesis (Fig. 1d).

Fourth component: the average range size within regions should be constant, regardless of latitude. It can be shown that $\beta=1 / \overline{\mathrm{p}}$, where $\beta$ is beta diversity within a region and $\bar{p}$ is the average range size of species occurring in that region, measured as the proportion of the total area of the region (Arita and Rodríguez 2002). Given this mathematical relationship, if beta is latitudeinvariant, then the average range size within regions should likewise be constant regardless of latitude. This measure of range size is different from the continental or global range size of species. We will call this measure the regional range size (RRS) to distinguish it from the continental range size.

Fifth component: $\mathrm{z}$, the slope of the log species-log area relationship (SAR) should be constant along the latitudinal gradient. Beta diversity and $\mathrm{z}$ are related by a direct mathematical relationship (Rosenzweig 1995, Arita and Rodríguez 2002), so under the hypothesis of covariation, if beta diversity is constant, then $\mathrm{z}$ should not vary with latitude.

Sixth component: if beta diversity remains constant, a Type I (linear) relationship should be produced when comparing the species diversity at both scales, using LR (local-regional) plots (Srivastava 1999). As pointed out by Rosenzweig and Ziv (1999), LR plots echo the 
information contained in the species-area relationship, so a constant $z$ should produce a linear LR plot. Then, if the hypothesis of covariation holds for a given set of regions and their corresponding localities, a linear LR relationship should be expected.

\section{Methods}

We constructed a database of the distribution of the mammals of North and Central America, including the mainland extending from Alaska and northern Canada to Panama. We built a list of 714 species of terrestrial mammals, not including introduced and insular species, and drew range maps for each species on an equal-area projection of North America, but updating the information with new taxonomic and distributional data published since then and up to the end of 2000. On each distribution map we overlaid a grid of sampling points separated by $50 \mathrm{~km}$ and, with the aid of an automated computer program designed with the technical support of the Mexican Commission on Biodiversity (CONA$\mathrm{BIO}$ ), we generated a database consisting of a presenceabsence matrix of 13195 sampling points and the species of mammals whose continental range overlap each point.

We sampled 21 regions each consisting of 64 of the sampling points of the database, arranged in a $8 \times 8$ pattern (see Arita and Rodríguez 2002, 2004 for additional details). Each of the regions measured 160000 $\mathrm{km}^{2}$. To reduce the non-independence of data between regions because of spatial autocorrelation (Pagel et al. 1991), we located them in such a way that the minimum distance between them was $1400 \mathrm{~km}$ in both latitudinal and longitudinal directions (Table 1). The regions were arranged to encompass a gradient extending from $20^{\circ}$ to $64^{\circ}$ north latitude. Because of the shape of the continent, there were more replicates in the northern section of the continent (six squares at $64^{\circ} \mathrm{N}$ ) than in southern Mexico (two squares at $20^{\circ} \mathrm{N}$ ). By using regions of standard size along the latitudinal gradient, we avoided the problems inherent when comparing units of differing size for the analysis of beta diversity (Koleff and Gaston 2001).

For each region we measured the regional diversity $\left(S_{R}\right)$ as the total number of species whose range intersected the square. We also calculated the RPD $\left(\overline{\mathrm{S}}_{\mathrm{RP}}\right)$ as the average number of species in the 64 sampling points within each region (Table 1). We calculated beta diversity using Whittaker's (1960) formula, $\beta=S_{R} / \bar{S}_{R P}$. We measured the regional range size (RRS) of each species as the proportion of sampling points of the region in which that species occurs. To calculate the slope $\mathrm{z}$ of the power function of the $\mathrm{SAR}, \mathrm{S}=\mathrm{cA}^{\mathrm{z}}$ (Rosenzweig 1995) we measured the average species diversity at two intermediate scales between the region and the sampling points by dividing the regions into 16 $10000-\mathrm{km}^{2}$ quadrats and four $40000-\mathrm{km}^{2}$ quadrats. Then, we estimated the slope of a straight line connecting the four log species-log area points corresponding to the four resultant scales. We did not evaluate here the shape of LR curves to test the sixth prediction of the

Table 1. Regional diversity (number of species whose range intersected the $160000 \mathrm{~km}^{2}$ sampling regions), regional point diversity (RPD) (average number of species in the 64 sampling points within each region) and regional range size (RRS) (average number of sampling points occupied by the species, expressed in percentage) and slope $\mathrm{z}$ calculated for species diversity at four scales: 2500 , 10000,40000 and $160000 \mathrm{~km}^{2}$.

\begin{tabular}{|c|c|c|c|c|c|c|c|c|c|}
\hline \multirow[t]{2}{*}{ Latitude } & \multirow[t]{2}{*}{ Longitude } & \multicolumn{4}{|c|}{ Non-volant mammals } & \multicolumn{4}{|c|}{ Chiroptera } \\
\hline & & $\begin{array}{l}\text { Regional } \\
\text { diversity }\end{array}$ & RPD & RRS & Slope z & $\begin{array}{l}\text { Regional } \\
\text { diversity }\end{array}$ & RPD & RRS & Slope z \\
\hline 64 & 158 & 34 & 29.65 & 87.22 & 0.03 & & & & \\
\hline 64 & 146 & 40 & 31.01 & 77.53 & 0.06 & & & & \\
\hline 64 & 134 & 40 & 36.39 & 90.98 & 0.02 & & & & \\
\hline 64 & 122 & 42 & 29.62 & 70.53 & 0.08 & & & & \\
\hline 64 & 110 & 34 & 20.89 & 61.44 & 0.12 & & & & \\
\hline 64 & 98 & 20 & 17.02 & 85.08 & 0.04 & & & & \\
\hline 52 & 122 & 68 & 47.04 & 69.17 & 0.09 & 14 & 8.20 & 58.59 & 0.13 \\
\hline 52 & 110 & 60 & 39.8 & 66.33 & 0.10 & 8 & 4.88 & 60.94 & 0.12 \\
\hline 52 & 86 & 41 & 33.11 & 80.75 & 0.05 & 3 & 2.58 & 85.94 & 0.04 \\
\hline 52 & 74 & 35 & 29.03 & 82.94 & 0.04 & & & & \\
\hline 40 & 122 & 109 & 51.03 & 46.81 & 0.18 & 16 & 13.72 & 85.73 & 0.08 \\
\hline 40 & 110 & 89 & 57.07 & 64.13 & 0.11 & 18 & 13.17 & 73.17 & 0.12 \\
\hline 40 & 98 & 65 & 46.18 & 71.05 & 0.09 & 14 & 8.28 & 59.14 & 0.12 \\
\hline 40 & 86 & 51 & 37.62 & 73.77 & 0.07 & 14 & 10.12 & 72.31 & 0.08 \\
\hline 28 & 110 & 99 & 44.02 & 44.46 & 0.20 & 47 & 27.72 & 58.98 & 0.13 \\
\hline 28 & 106 & 93 & 50.7 & 54.52 & 0.15 & 43 & 24.53 & 57.05 & 0.12 \\
\hline 28 & 102 & 84 & 49.07 & 58.42 & 0.13 & 32 & 19.59 & 61.22 & 0.12 \\
\hline 24 & 106 & 108 & 47.1 & 43.61 & 0.20 & 59 & 35.92 & 60.88 & 0.18 \\
\hline 24 & 102 & 105 & 50.14 & 47.75 & 0.18 & 57 & 27.13 & 47.59 & 0.15 \\
\hline 20 & 102 & 122 & 47.56 & 38.98 & 0.23 & 79 & 42.34 & 53.59 & 0.17 \\
\hline 20 & 98 & 133 & 55.94 & 42.05 & 0.21 & 100 & 49.37 & 49.37 & 0.14 \\
\hline
\end{tabular}

*Because of the reduced number of bat species in the northern part of the hemisphere $(<4$ species $)$, data of Chiroptera corresponding to latitudes $64^{\circ}$ and $52^{\circ}$ are excluded from the statistical analyses. 
hypothesis of covariation, but did so elsewhere using the same database (Arita and Rodríguez 2004).

To assess the degree to which latitude affects beta diversity, RRS and the parameter $\mathrm{z}$ of the SAR we performed non-parametric analyses (Spearman's rank correlation). Bats and non-volant mammals present contrasting patterns of distribution in North America. The frequency distribution of the size of distributional ranges is significantly different between the two groups (Pagel et al. 1991), and the geographical pattern of species diversity is also different between volant and non-volant mammals. Consequently, we conducted separate analyses for the two groups.

\section{Results}

We found latitudinal gradients of species richness for bats at the two scales of analysis. Regional diversity varied from 100 to 3 species along the gradient, being highest in southern Mexico $\left(\mathrm{r}^{2}=0.88, \mathrm{p}<0.05, \mathrm{~N}=14\right.$, Figs $2 \mathrm{a}$ and $3 \mathrm{a}$ ). RPD also decreased from southern latitudes from 50 to 2.6 species, showing a peak in southern Mexico $\left(\mathrm{r}^{2}=0.89, \mathrm{p}<0.05, \mathrm{~N}=14\right.$, Figs $2 \mathrm{~b}$ and $3 \mathrm{a}$ ). Non-volant mammals also showed a latitudinal gradient at both scales. Regional diversity decreased from south to north from 133 to 20 species, being highest in southern Mexico, at $20^{\circ}$ north latitude $\left(\mathrm{r}^{2}=0.80\right.$, $\mathrm{p}<0.05, \mathrm{~N}=21$, Figs $2 \mathrm{c}$ and $4 \mathrm{a})$. RPD also decreased from south to north, from 56 to $17\left(\mathrm{r}^{2}=0.60, \mathrm{p}<0.05\right.$, $\mathrm{N}=21$, Figs $2 \mathrm{~d}$ and $4 \mathrm{a}$ ).

In the case of bats, a linear statistical model failed to demonstrate a significant difference in the slopes of the two $\log$ species-latitude lines $\left(\mathrm{m}_{\mathrm{R}}=-0.039\right.$, $\mathrm{m}_{\mathrm{RP}}=-0.032, \mathrm{~F}_{1,28}=1.1, \mathrm{p}=0.21$, Fig. 3a), that is, the increase in diversity from north to south occurs at the same rate regardless of the scale of analysis (case in Fig. 1b), failing to reject the hypothesis of covariation.

\section{Volant mammals}

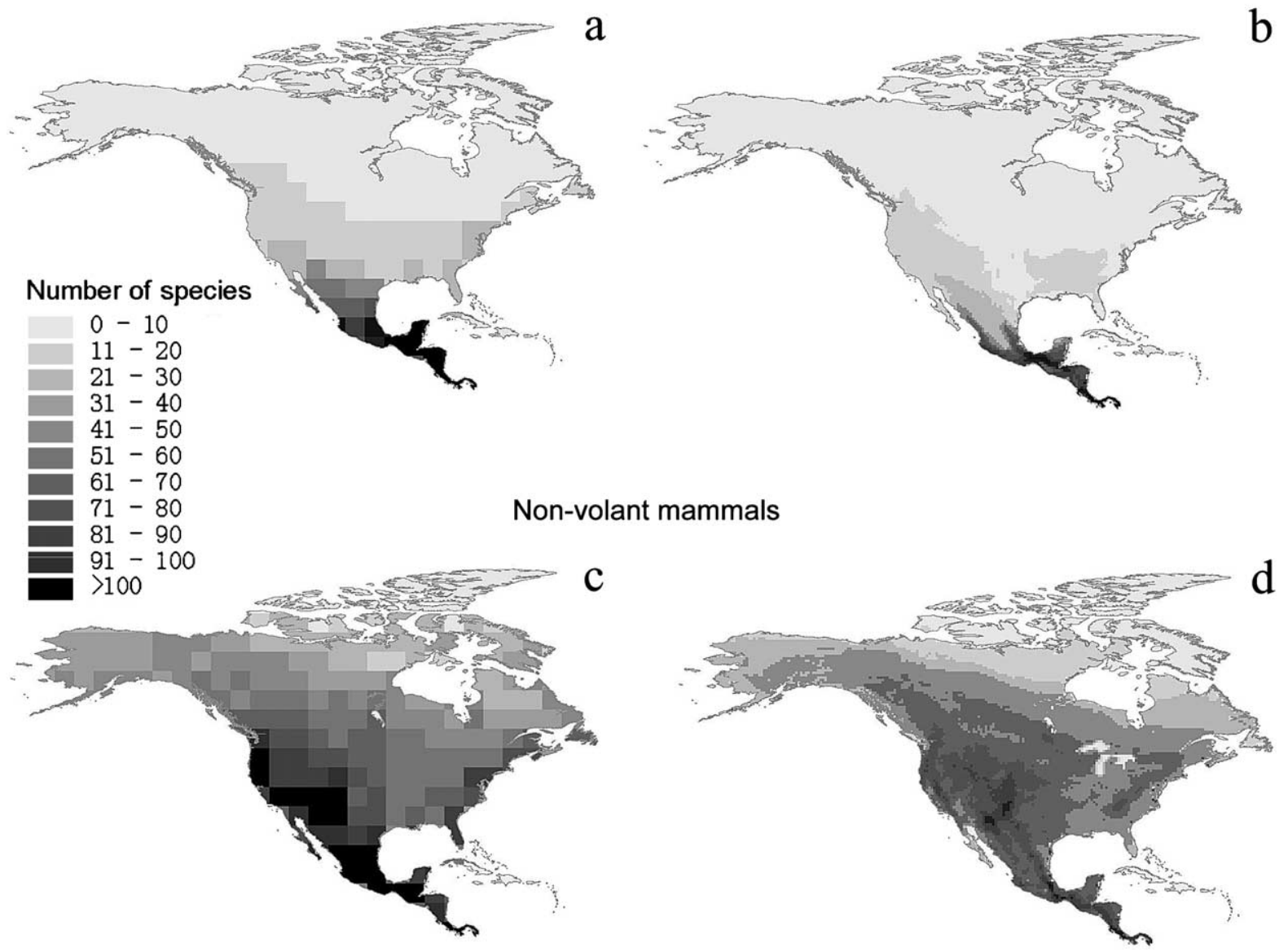

Fig. 2. Latitudinal pattern of species diversity in the North American mammal fauna at two scales: regional scale (squares of $160000-\mathrm{km}^{2}$ squares (a) and regional point diversity (RPD) (sampling points separated by $50 \mathrm{~km}$ (b) for the North American bats. Regional (c) and RPD (d) for North American non-volant mammals. 

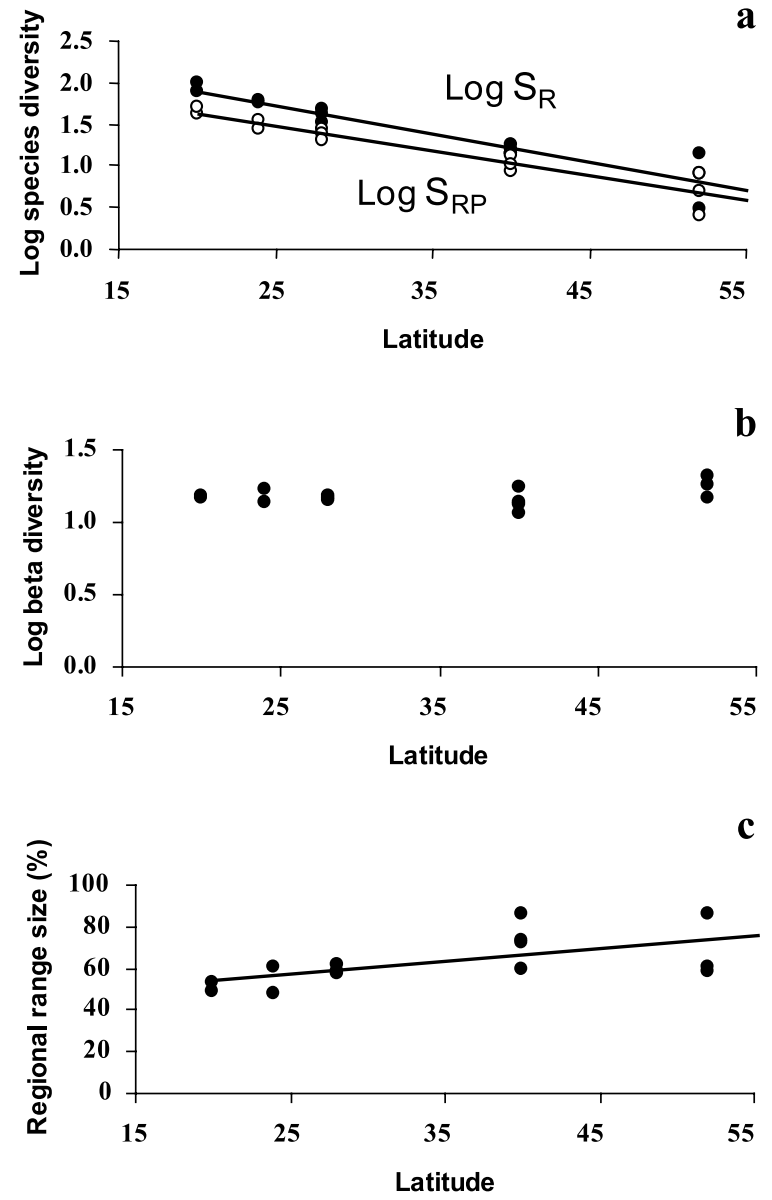

d

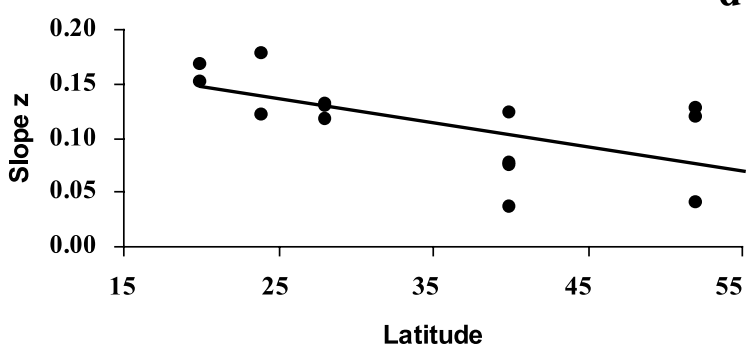

Fig. 3. Latitudinal patterns of diversity for the North American bats. Latitudinal gradient of species diversity at the regional scale (squares of $\left.160000 \mathrm{~km}^{2}\right)\left(\mathrm{r}^{2}=0.88, \mathrm{p}<0.05, \mathrm{~N}=14\right)$, and regional point diversity (RPD) (sampling points separated by 50 $\mathrm{km})\left(\mathrm{r}^{2}=0.89, \mathrm{p}<0.05, \mathrm{~N}=14\right)(\mathrm{a})$. Latitudinal pattern of beta diversity $\left(r^{2}=0.08, p>0.05, N=14\right)(b)$. Latitudinal pattern of the regional range size of species within the regions $\left(\mathrm{r}^{2}=0.35\right.$, $\mathrm{p}<0.05, \mathrm{~N}=14)$ (c). Latitudinal gradient of $\mathrm{z}$, the slope of the species-area relationship $\left(r^{2}=0.39, p<0.05, N=14\right)(d)$.

Having established the parallelism of the lines, an analysis of covariance showed a significant effect of scale $\left(\mathrm{F}_{1,28}=14.37, \mathrm{p}<0.001\right)$, demonstrating a difference between the species diversity at the two scales, therefore showing a significant effect of beta diversity. Although diversity of non-volant mammals decreased with latitude at both scales of analysis, it did so at different rates. The linear model demonstrated a significant interaction between scale and latitude, showing that the slopes of the log species-latitude lines were different for the two scales, with a steeper slope for regional diversity $\left(\mathrm{m}_{\mathrm{R}}=-0.0126, \mathrm{~m}_{\mathrm{RP}}=-0.0066\right.$, $\mathrm{F}_{1,40}=4.71, \mathrm{p}=0.03$, Fig. 4a), that is, the latitudinal gradient is more obvious at the larger scale, therefore rejecting the hypothesis of covariation.

We found a significant relationship between beta diversity and latitude for non-volant mammals $\left(\mathrm{r}^{2}=0.63, \mathrm{p}<0.05, \mathrm{~N}=21\right.$, Fig. $\left.4 \mathrm{~b}\right)$, but not for bats $\left(r^{2}=0.08, p>0.05, N=14\right.$, Fig. 3b). For non-volant mammals, beta diversity followed a general trend of increasing from north to south, and the peak values were observed at latitude $20^{\circ}$, corresponding to southern Mexico. These results are consistent with those of the previous section, rejecting the hypothesis of covariation for non-volant mammals, but not for bats.

Figures $3 \mathrm{c}$ and $4 \mathrm{c}$ show the relationship between RRS, measured as the proportion of sampling points within a large square in which a species occurs, and latitude. Non-volant mammals showed a trend in which RRS is larger at higher latitudes $\left(\mathrm{r}^{2}=0.71, \mathrm{p}<0.05, \mathrm{~N}=21\right.$, Fig. 4c). RRS in bats is larger at higher latitudes but the relationship with latitude was weaker but still significant $\left(\mathrm{r}^{2}=0.35, \mathrm{p}<0.05, \mathrm{~N}=14\right.$, Fig. 3c). Because the average range size of species within a region is equal to the inverse of beta diversity among sites within that region (Arita and Rodríguez 2002), values of the correlation coefficients are also significant but with different sign.

Our analysis of the slope $\mathrm{z}$ of the species-area relationship within regions showed differences between bats and non-volant mammals. Bat $\mathrm{z}$ did vary with latitude $\left(r^{2}=0.39, p<0.05, N=14\right)$ and showed low values (from $\mathrm{z}=0.04$ to $\mathrm{z}=0.18$ ) (Fig. 3d, Table 1). Non-volant mammals showed a more significant variation in the slope $\mathrm{z}$ along the latitudinal gradient $\left(\mathrm{r}^{2}=0.71, \mathrm{p}<0.05, \mathrm{~N}=21\right)$, and the rate of change of $\mathrm{z}$ was faster in southern latitudes $(\mathrm{z}=0.23)$ (Fig. $4 \mathrm{~d})$.

\section{Discussion}

\section{Latitudinal gradients of species diversity}

Our results confirm the latitudinal gradient in bat species diversity in North America. This latitudinal pattern holds regardless of the different scales at which richness has been measured and the different methods that have been used, and is valid even at the scale of localities (Stevens and Willig 2000). While North American Neotropical bat communities can consist of up to 64 species, most bat communities in the United States and in Canada are formed by ten species or less. The 

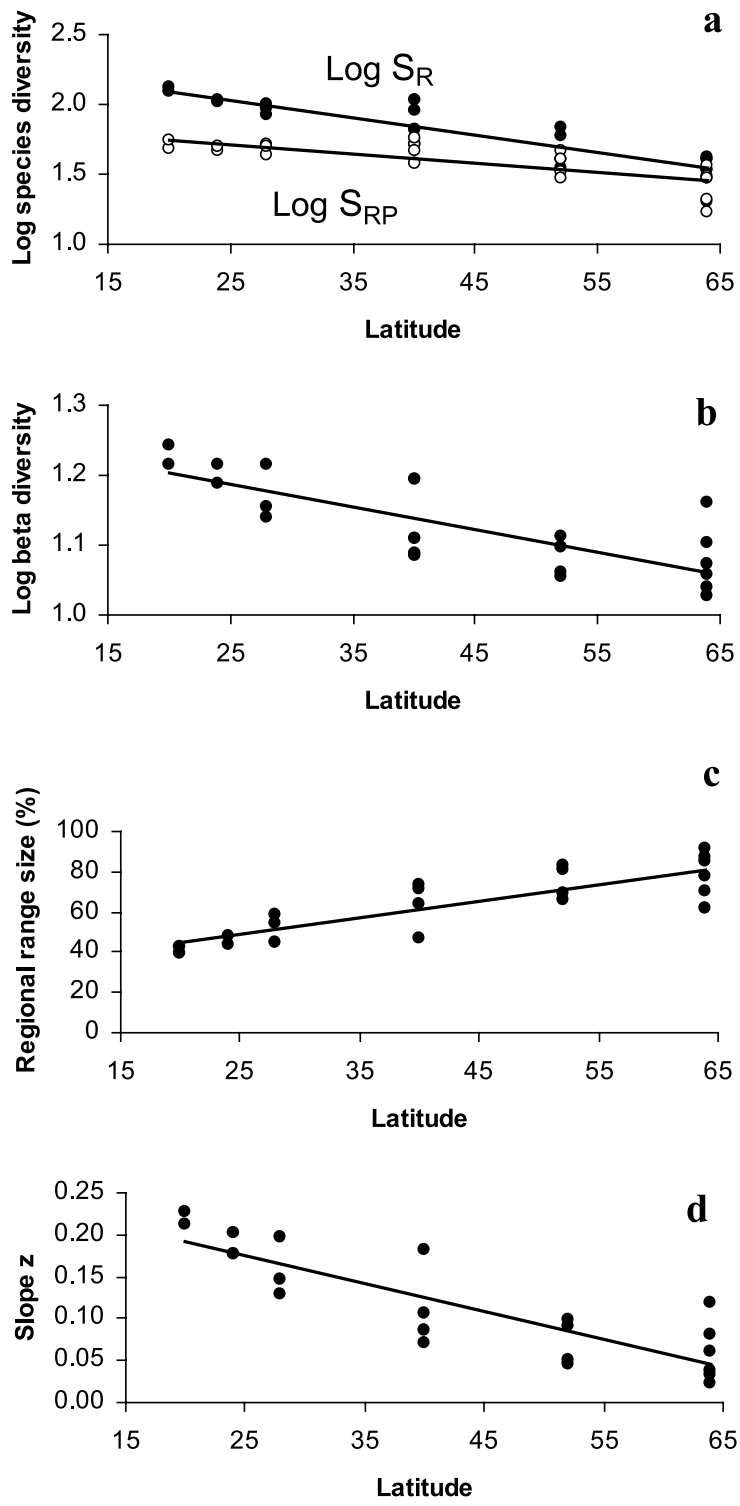

Fig. 4. Latitudinal patterns of diversity for the North American non-volant mammal fauna. Latitudinal gradient of species diversity at the regional scale (squares of $\left.160000 \mathrm{~km}^{2}\right)\left(\mathrm{r}^{2}=\right.$ $0.80, \mathrm{p}<0.05, \mathrm{~N}=21$ ), and regional point diversity (RPD) (sampling points) $\left(\mathrm{r}^{2}=0.60, \mathrm{p}<0.05, \mathrm{~N}=21\right)(\mathrm{a})$. Latitudinal pattern of beta diversity $\left(\mathrm{r}^{2}=0.63, \mathrm{p}<0.05, \mathrm{~N}=21\right)$ (b). Latitudinal pattern of the regional range size of species within the regions $\left(\mathrm{r}^{2}=0.70, \mathrm{p}<0.05, \mathrm{~N}=21\right)(\mathrm{c})$. Latitudinal gradient of $\mathrm{z}$, the slope of the species-area relationship $\left(\mathrm{r}^{2}=0.72\right.$, $\mathrm{p}<0.05, \mathrm{~N}=21)(\mathrm{d})$.

gradient of bats is related to the absence in the Nearctic region of most of the feeding guilds characteristic of the Neotropical realm. All bat species north of ca $35^{\circ}$ north latitude are insectivorous, whereas tropical habitats are inhabited by complex assemblages of species with different feeding habits (Willig and Sandlin 1991, Willig et al. 2003).
We did not detect a difference between the slopes of the two log species-latitude plots, a result that contrasts with that of Lyons and Willig (2002) and with that of Stevens and Willig (2002). Lyons and Willig (2002) measured species diversity at 10 scales, encompassing areas from $1000 \mathrm{~km}^{2}$ to $25000 \mathrm{~km}^{2}$ (an order of magnitude smaller than our regions). They used the parameter $\log \mathrm{c}$ of the $\log$ species-log area equation (the ordinate to the origin), to generate a value of species richness independent of area. They found gradients of bat species diversity at all scales, but documented differences in the rate of increase of diversity towards southern latitudes. Stevens and Willig (2002) measured number of species at two scales: regional diversity (similar to our regional diversity) and local diversity (species richness at a single habitat). They also found differences in the rate of increase of diversity towards southern latitudes being much more pronounced at the regional scale. This discrepancy can be the result of the difference in methodology, or might reflect, in both cases, a true change in the latitudinal pattern at smaller scales.

Our results also confirm the latitudinal gradient of species diversity for non-volant mammals (Pagel et al. 1991, Kaufman 1995, Kaufman and Willig 1998). Only one study has failed to find a latitudinal gradient of species diversity for North American non-volant mammals (McCoy and Connor 1980, see also Pagel et al. 1991). This discrepancy can be explained by the method and scales that those authors used. McCoy and Connor (1980) measured species richness in bands of one degree arranged at different latitudes, and computed the diversity without controlling the effect of variation in length of their bands. Therefore, they compared very long bands in northern North America (where the continent is wider) to shorter bands in Mexico and Central America. Additionally, their method did not control for the effect of species turnover along the bands (Kaufman and Willig 1998).

Our finding that the gradient in species diversity of non-volant mammals is less obvious at smaller scales is consistent with the results of Kaufman (1995), who found a significant but weak linear relationship of species diversity and latitude when comparing local mammal communities. Moreover, preliminary results of an on-going project suggest that the latitudinal gradient of diversity of North American non-volant mammals is less perceptible at the scale of localities (Rodríguez and Rodríguez-Tapia unpubl.). This indicates that although RP assemblages of non-volant mammals tend to be formed by approximately the same number of species along the North American continent, the regional pools are more diverse at lower latitudes. 


\section{Latitudinal gradient of beta diversity}

Brown and Lomolino (1998; p. 470), based on data from Kaufman for North American mammals (1998), assumed that beta diversity should increase with decreasing latitude, a pattern consistent with our results for non-volant mammals, but not for bats. Kaufman's original data are pairs of diversity values formed by one locality and its corresponding region, beta being measured as the proportion of species of the pool (the region) occurring at the locality. Additionally, no data were available for areas south of the Mexico-US border, an area in which we found the highest variation in beta diversity. Our results also support the idea that the unusually high species richness of non-volant mammals in large-scale areas of Mexico is the result more of a higher beta diversity at the corresponding latitudes than a consequence of small scale assemblages being particularly rich in species.

In contrast with non-volant mammals, beta diversity for bats did not show a latitudinal trend, a result that fails to reject the hypothesis of covariation. This result is not consistent with the observations of Willig and Sandlin (1991) who, using a different method (species turnover along latitudinal bands) and working at a different scale (quadrats and bands of $5^{\circ}$ latitude) found a positive relationship between species turnover and latitude. Our results appear to contradict the recent finding of Stevens and Willig (2002) of an increase in beta diversity towards tropical latitudes when comparing local communities with their corresponding regional pools. This result suggests a possible break in the scaling rules as the sampling grain becomes very small. At least for North American bats, it seems that local interactions might be important in shaping the communities, a pattern that cannot be discerned at the scales of our comparisons. The discrepancy might also reflect that our study included few areas in the tropics. In fact Stevens and Willig (2002) indicated greater beta diversity toward the equator. It could possible be that a greater range of latitudes is necessary to detect patterns of beta diversity for bats than for non-volant mammals.

\section{Latitudinal variation in range size (RRS)}

Our empirical results for bats illustrate how gradients in species diversity can be generated without an obvious trend in RRS. For chiropteran species, the most diverse regions contain both widespread and restricted species. These results are in concordance with the explanation posited by Lyons and Willig (2002) regarding the latitudinal pattern of bat diversity in the New World. Our results for non-volant species show that latitudinal gradients of species diversity can be also generated when species with restricted distribution are concentrated in the areas of higher diversity. This pattern is the expected outcome of Rapoport's rule (Stevens 1989), and is incompatible with the predictions of mid-domain models (Colwell and Lees 2000, Koleff and Gaston 2001, Bokma et al. 2001, Zapata et al. 2003). It is important to emphasize here, however, that what we measured was the range sizes within the regions, and not on the whole continent.

If the mid-domain effect cannot explain the pattern of diversity of non-volant mammals, then, what are the alternative explanations? Why is average range smaller (and thus beta diversity higher) in Mexico than in Central America? Available information suggests that two are the main factors determining this pattern: firstly, the high environmental heterogeneity of southern Mexico creates a spatial mosaic that precludes species to be widespread (Arita and Rodríguez 2002); secondly, the convergence in Mexico of two of the major biogeographic realms, the Nearctic and the Neotropical, produces a pattern in which several species reach their northernmost or southernmost distribution within Mexico. The range size of these species within a given region in Mexico is effectively small, even though they can be very widespread elsewhere in the continent.

A possible explanation for the contrasting pattern for bats and non-volant mammals could be related to dispersal ability. Because non-volant mammals are less mobile animals than bats, they are probably more sensitive to physiographic barriers to dispersal and have lower capabilities of colonizing new areas, and their ranges are probably limited mostly by regional heterogeneity. In contrast, bats, which are more mobile animals, are less limited by topographic features, and their ranges are probably determined by continentalwide patterns of climatic conditions (Arita and Rodríguez 2004).

\section{Latitudinal gradient of $z$}

We found a weak but significant relationship between zeta values of bats and latitude, being higher at tropical latitudes. Our results differ from the pattern found by Lyons and Willig (2002) who reported decreasing values of $\mathrm{z}$ toward tropical latitudes. According to their explanation, ranges for bats are larger and overlap higher in the tropics (Lyons and Willig 1997) dimishing the rate at which species richness increases with area. However they reported outliers at latitudes 20 to $30^{\circ}$, perhaps due to the small number of samples at that latitude or have distinct biological importance, as these locations occurs at the interface of tropical and temperate biomes in Mexico. Our results of $\mathrm{z}$ values and average range size support the Lyons and Willig's (2002) speculation that those latitudes correspond to the Trans Mexican Volcanic Belt (Arita and Rodríguez 2002). Range for bats are smaller in this biogeographic and 
ecologically complex region and as a consequence the rate at which species richness increases with area $(\mathrm{z})$ is higher compared to other latitudes.

This pattern of faster species accumulation in southern latitudes is much more pronounced in non-volant mammals. In the case of non-volant mammals, we documented a clear increase in the value of $\mathrm{z}$ towards southern latitudes, mirroring the gradual decrease in the average range size. As the average range decreases at tropical latitudes, the species turnover increases, producing a faster accumulation of species as sampling area increases, therefore yielding higher values of $\mathrm{z}$.

\section{Shape of the local-regional species diversity relationship}

Results of a parallel study using the same database for North American mammals (Arita and Rodríguez 2004) show that when comparing the species diversity of the large squares with the average diversity of the sampling points within them, and graphing the pairs of points in a SRLR (small region to large region) plot analogous to standard LR plots (Cornell and Lawton 1992), a Type I (linear) relationship is produced for bats, and a Type II (saturating) curve is generated for non-volant mammals. As pointed out by Srivastava (1999), a Type I relationship implies a constant value of beta diversity, whereas a Type II curve implies a decreasing beta as the regional diversity increases. Thus, the results reported in Arita and Rodríguez (2004) are consistent with the prediction of the hypothesis of covariation: bats, which show no latitudinal variation in beta diversity, show a Type I SRLR relationship, and non-volant mammals, which present a distinct gradient of beta, produce a Type II SRLR curve.

As demonstrated mathematically, there is a direct link between the type of SRLR curves and the patterns in the distribution of species (Arita and Rodríguez 2004). In particular, the variation in average range size as the regional diversity increases is what ultimately determines the shape of the curves. Therefore, as the hypothesis of covariation predicts, if the RRS remains constant when comparing several regions, then both beta diversity and $\mathrm{z}$ should be also constant, and the corresponding LR plot should be linear.

\section{Conclusions: linking the patterns}

The hypothesis of covariation explicitly provides a framework to link several macroecological patterns that, at first glance, would seem to be unrelated. In particular, the six components of the hypothesis provide specific predictions that can be directly tested with empirical data. The hypothesis also shows that fundamental variables, such as beta diversity and $\mathrm{z}$, the slope of the species-area relationship, are determined ultimately by the patterns in the spatial distribution of species, and, more specifically, by the average range size.

As discussed by Arita and Rodríguez (2004), the shape of SRLR plots depend solely on the average regional range of species, and is independent of their shape and location. The same argument can be extended to beta diversity and $\mathrm{z}$. If, within regions, one could deform and move the ranges of species, with the only condition of conserving their size, beta diversity, $z$, and the shape of the SRLR relationship would not change. In the context of the hypothesis of covariation, the gradient of species diversity at different scales would also remain intact. Moreover, even changing the size of individual ranges, provided that their average is not modified, would not produce variations in beta, $z$, or the shape of SRLR plots.

Therefore, the ultimate factor determining the patterns of distribution and scaling of diversity at large scales is the arrangement of species in continental space. In other words, at the center of the discussion on largescale patterns of diversity is the basic question postulated by macroecology, that is, how species share resources at regional and continental scales (Brown and Maurer 1989).

Acknowledgements - Funding for this project was provided by DGAPA-UNAM and by the Mexican Commission of Biodiversity (CONABIO). We thank G. Guerrero, J. Uribe, and L. B. Vázquez for technical support. G. Rodríguez-Tapia for efficient help with the database analysis, and to A. Christen, J. Soberón and E. Vázquez-Domínguez for insightful discussions. P. Rodríguez participated with the support of a scholarship from DGEP-UNAM for graduate studies in the Biomedical Sciences Doctoral Program of UNAM.

\section{References}

Arita, H. T. and Rodríguez, P. 2002. Geographic range, turnover rate and the scaling of species diversity. - Ecography 25: $541-553$.

Arita, H. T. and Rodríguez, P. 2004. Local-regional relationships and the geographic distribution of species. - Global Ecol. Biogeogr. 13: 15-21.

Bokma, F., Bokma, J. and Mönkkönen, M. 2001. Random processes and geographic species richness patterns: why so few species in the north? - Ecography 24: 43-49.

Brown, J. H. and Maurer, B. A. 1989. Macroecology: the division of food and space among species on continents. - Science 243: 1145-1150.

Brown, J. H. and Lomolino, M. V. 1998. Biogeography, 2nd ed. - Sinauer.

Colwell, R. K. and Lees, D. C. 2000. The mid-domain effect: geometric constraints on the geography of species richness. - Trends Ecol. Evol. 15: 70-76.

Condit, R. et al. 2002. Beta diversity in tropical forest trees. - Science 295: 666-669.

Cornell, H. V. and Lawton, J. H. 1992. Species interactions, local and regional processes, and limits to the richness of ecological communities: a theoretical perspective. - J. Anim. Ecol. 61: 1-12.

Crawley, M. J. and Harral, J. E. 2001. Scale dependence in plant biodiversity. - Science 291: 864-868. 
Gaston, K. J. and Blackburn, T. M. 2000. Pattern and process in macroecology. - Blackwell.

Hawkins, B. A. and Diniz-Filho, J. A. F. 2002. The mid-domain effect cannot explain the diversity gradient of Neartic birds. - Global Ecol. Biogeogr. 11: 419-426.

Jetz, W. and Rahbek, C. 2001. Geometric constrains explain much of the species richness pattern in African birds. - Proc. Natl. Acad. Sci. USA 98: 5661-5666.

Kaspari, M., Yuan, M. and Alonso, L. 2003. Spatial grain and the causes of regional diversity gradients in ants. - Am. Nat. 161: 460-477.

Kaufman, D. M. 1995. Diversity of New World mammals: university of latitudinal gradients of species and bauplans. - J. Mammal. 76: 322-334.

Kaufman, D. M. 1998. The structure of mammalian faunas in the New World: from continents to communities. - Ph.D. thesis, Univ. of New Mexico.

Kaufman, D. M. and Willig, M. R. 1998. Latitudinal patterns of mammalian species richness in the New World: the effects of sampling method and faunal group. - J. Biogeogr. 25: 795-805.

Koleff, P. and Gaston, K. J. 2001. Latitudinal gradients in diversity: real patterns and random models. - Ecography 24: $341-351$.

Koleff, P., Gaston, K. J. and Lennon, J. J. 2003. Measuring betadiversity for presence absence data. - J. Anim. Ecol. 72: $367-382$.

Lyons, S. K. and Willig, M. R. 1997. Latitudinal patterns of range size: methodological concerns and empirical evaluations for New World bats and marsupials. - Oikos 79: $568-$ 580.

Lyons, S. K. and Willig, M. R. 1999. A hemispheric assessment of scale dependence in latitudinal gradients of species richness. - Ecology 80: 2483-2491.

Lyons, S. K. and Willig, M. R. 2002. Species richness, latitude and scale-sensitivity. - Ecology 83: 47-58.

McCoy, E. D. and Connor, E. F. 1980. Latitudinal gradients in species diversity of North American mammals. - Evolution 24: 193-203.

Pagel, M. D., May, R. M. and Collie, A. R. 1991. Ecological aspects of the geographical distribution and diversity of mammalian species. - Am. Nat. 137: 791-815.

Rapoport, E. H. 1975. Areografía: estrategias geográficas de las especies. - Fondo de Cultura Económica, Mexico City.

Ricklefs, R. E. 2004. A comprehensive framework for global patterns in biodiversity. - Ecol. Lett. 7: 1-15.

Ricklefs, R. E. and Schluter, D. 1993. Species diversity in ecological communities: historical and geographical perspectives. - Univ. of Chicago Press.

Rohde, K. 1999. Latitudinal gradients in species diversity and Rapoport's rule revisited: a review of recent work and what parasites teach us about the causes of the gradient? - Ecography 22: 593-613.

Rosenzweig, M. L. 1995. Species diversity in space and time. - Cambridge Univ. Press

Rosenzweig, M. L. and Ziv, Y. 1999. The echo pattern of species diversity: pattern and processes. - Ecography 22: 614-618.

Routledge, R. D. 1977. On Whittaker's components of diversity. - Ecology 58: 1120-1127.

Shepherd, U. L. 1998. A comparison of species diversity and morphological diversity across the North American latitudinal gradient. - J. Biogeogr. 25: 19-29.

Shmida, A. and Wilson, M. V. 1985. Biological determinants of species diversity. - J. Biogeogr. 12: 1-20.

Simpson, G. G. 1964. Species density of North American Recent mammals. - Syst. Zool. 13: 57-73.

Srivastava, D. S. 1999. Using local-regional richness plots to test for species saturation: pitfalls and potentials. - J. Anim. Ecol. 68: 1-16.

Stevens, G. C. 1989. The latitudinal gradient in geographical range: how so many species coexist in the tropics. - Am. Nat. 133: 240-256.

Stevens, R. D. and Willig, M. R. 2002. Geographical ecology at the community level: perspectives on the diversity of New World bats. - Ecology 83: 545-560.

Whittaker, R. H. 1960. Vegetation of the Siskiyou Mountains, Oregon and California. - Ecol. Monogr. 30: 279-338.

Whittaker, R. H. 1972. Evolution and measurement of species diversity. - Taxon 21: 213-251.

Williams, P. H., de Klerk, H. M. and Crowe, T. M. 1999 Interpreting biogeographical boundaries among Afrotropical birds: spatial patterns in richness gradients and species replacement. - J. Biogeogr. 26: 459-474.

Willig, M. R. and Sandlin, E. A. 1991. Gradients of species density and species turnover in New World bats; a comparison of quadrats and band methodologies. - In: Mares, M. A. and Schmidly, D. J. (eds), Latin American mammalogy. History, biodiversity and conservation. Univ. Oklahoma Press, Norman, pp. 81-96.

Willig, M. R. and Gannon, M. R. 1997. Gradients of species density and turnover in marsupials: a hemispheric perspective. - J. Mammal. 78: 756-765.

Willig, M. R., Patterson, B. D. and Stevens, R. D. 2003. Patterns of range size, richness, and body size in Chiroptera. - In: Kunz, T. H. and Fenton, M. B. (eds), Bat ecology. Univ. of Chicago Press, pp. 580-621.

Wilson, J. W. Jr 1974. Analytical zoogeography of North American mammals. - Evolution 28: 124-140.

Zapata, F. A., Gaston, K. J. and Chown, S. L. 2003. Mid-domain models of species richness gradients: assumptions, methods and evidence. - J. Anim. Ecol. 72: $677-690$. 